POLICY

\section{Clinical research: Should patients pay to play?}

\section{Ezekiel J. Emanuel, ${ }^{1}$ Steven Joffe, ${ }^{1}$ Christine Grady, ${ }^{2}$ David Wendler, ${ }^{2}$ Govind Persad ${ }^{3}$}

Permitting patients to pay for participation in clinical research threatens the principles of social value and fair subject selection as well as robust clinical trial design.

Paying people for their participation in research has long engendered controversy (1). Payments, some argue, can be an undue inducement that exposes participants to unnecessary risks and undermines the voluntary nature of informed consent. Although some disagreement remains, these charges have now largely been refuted by both argument and data $(2,3)$. But what about the opposite: Is it permissible for researchers to charge people to participate in research studies that offer some potential for clinical benefit?

Charging for research participation is not a new idea $(4,5)$. Certainly, many research participants bear costs to participate in research, such as those related to travel, parking, and time off of work (2). But both the magnitude of clinical trial-related costs and linking payment to enrollment make charging for participation different. Previously, unscrupulous companies and health facilities have charged for research participation to increase profits $(5,6)$. Many of these companies went bankrupt $(5,6)$.

The idea of charging research subjects for their participation has been resurrected primarily by clinical researchers who are understandably frustrated with the shrinking budgets (in real dollars) of the U.S. National Institutes of Health (NIH) and other research sponsors. They propose to charge research participants as a way of funding studies that otherwise would not be conducted because of limited resources.

One of us (E.J.E.) was asked to advise a group of academic investigators about the legality and ethics of charging for enrollment in an early-phase clinical study de-

'Department of Medical Ethics and Health Policy, Perelman School of Medicine, University of Pennsylvania Philadelphia, PA 19146-6303, USA. ²Department of Bioethics, Clinical Center, U.S. National Institutes of Health, Bethesda, MD 20892, USA. '3Department of Philosophy, Stanford University, Stanford, CA 94305-2155, USA.

*Corresponding author. E-mail:vp-global@upenn.edu signed to assess the accuracy and efficacy of an experimental precision-medicine diagnostic test that might help target therapies. These researchers-and others-argue that the lack of resources precludes the evaluation of potentially promising tests, drugs, and other interventions and that requiring payment from study participants might help support encouraging but currently unfunded and thus fallow research. The clinical studies would otherwise fulfill all of the traditional scientific and ethical requirements: a valuable hypothesis, detailed protocol, institutional review board (IRB) approval, informed consent documents and discussions, and commitment to disseminate all findings through scientific presentations and publication in journal articles.

Clinical and translational research is expensive. In the past, researchers have charged patients up to $\$ 35,000$ for enrollment in a study and access to experimental interventions $(5,6)$. In the proposed precision-

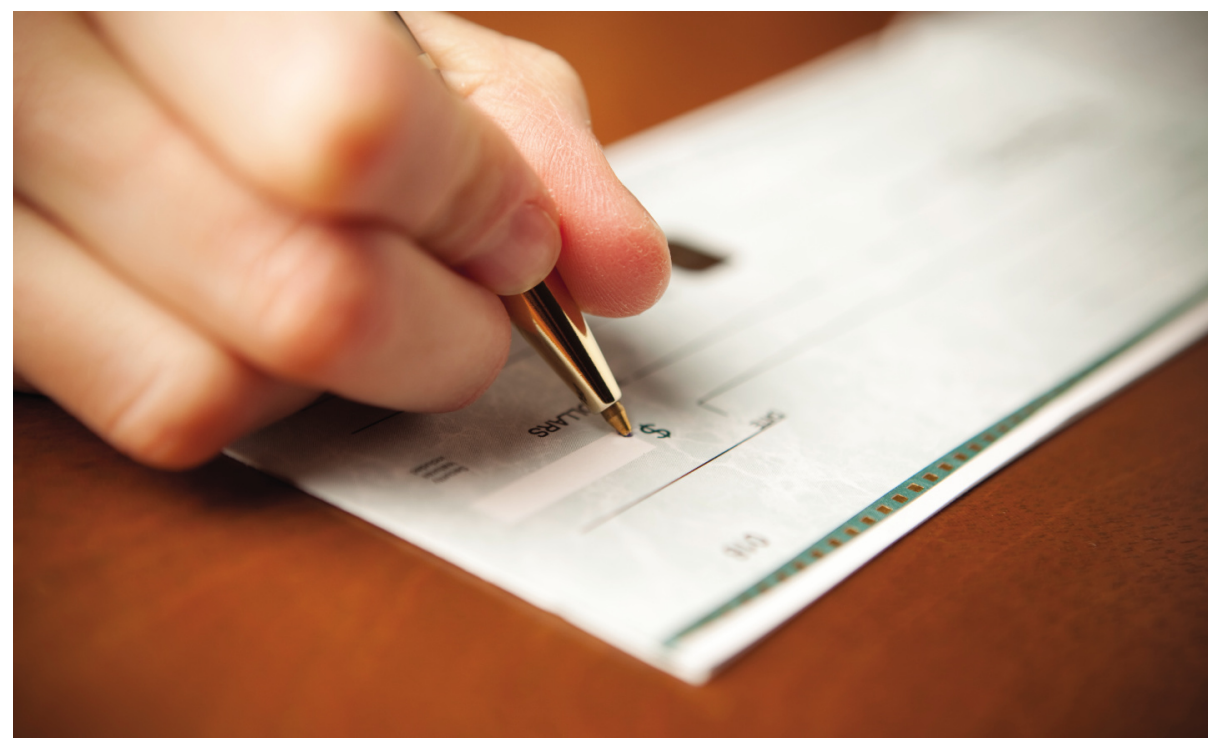

Pay to play raises the specter of exploitation of trial participants and their families and threatens principles of social value, fair subject selection, and robust clinical trial design. medicine diagnostic study, researchers envision charging $\$ 20,000$ to $\$ 30,000$, depending on the estimated cost of the research.

Resource constraints in medicine and research are not new, but they are becoming more severe. Currently, there are constrained collective resources, and patients are asked to bear an increasing proportion of their medical costs through highdeductible health plans and other mechanisms. Consequently, it might seem natural to ask participants-who have the potential to benefit from research trials-to contribute financially to the costs of their research.

There do not appear to be any clear legal or regulatory prohibitions on charging for participation in a research study. What are the ethical arguments for and against this practice?

Answering this question involves consideration of the foundational principles of ethical research: collaborative partnership, social value, scientific validity, fair subject selection, favorable risk-benefit ratio, informed consent, and protecting the welfare of enrolled participants (7).

\section{ARGUMENTS IN SUPPORT OF PAY TO PLAY}

Advocates might marshal five main ethical arguments to support charging for participation in a research study. First, requiring payment for research participation could enhance collaborative partnership. Paying for participation is literally "putting your money where your mouth is." Payment would be a real sign of participant 
engagement-indeed, identification-with the particular protocol. What could demonstrate partnership more than a personal financial investment?

Second, new sources of funding for clinical research could enhance social value by supporting studies that otherwise might not be conducted because of resource constraints. As long as the research answers an important question, is conducted rigorously, and the results-positive or negativeare disseminated, social value increases. The more biomedical research is conducted, the more society learns about what drugs, devices, diagnostics, or other interventions work and do not work. Even research studies that produce negative results offer social value by revealing mistaken leads and redirecting resources to other more promising opportunities. As such, when it funds socially valuable research, "pay to play" could be considered an act of charity-a donation for scientific advancement. Through disease-based charities, such as the American Cancer Society, or donations to academic research centers to fund professorships or specific laboratories, people often support biomedical research as a charitable contribution. Participant-funded research simply represents a more direct way of funding research-an analog of the crowdfunding website Kickstarter (www.kickstarter.com) for clinical research. Indeed, when viewed as a charitable contribution, payment for research seems worthier than spending the equivalent amount on a luxury car, jewelry, or an exotic vacation. Supporting research that is socially valuable transmutes personal consumption into a charitable contribution that benefits everyone.

Third, having people pay to participate in research could affirm-perhaps even enhance-informed consent. It is likely that people who invest their own resources to participate in research will analyze informed consent documents more carefully and thus better understand what they are getting into-and investing in $(3,8)$. Furthermore, signing one's name not just to an informed consent document but to a substantial check is a tangible affirmation of people's voluntariness.

Fourth, there is a precedent for pay to play. Paying for research participation might not appear to be different from expanded access to experimental agents. Assuming certain conditions are met, the U.S. Food and Drug Administration (FDA) allows patients who have exhausted other therapeutic options to obtain experimental treatments even outside the confines of a clinical trial (9). In such cases, companies are permitted to charge the patients in order to pay for the cost of the experimental drug or biological agent. Pay-to-play arrangements, it might be argued, are no different.

Last, there is a liberty argument. It is widely accepted by ethicists and political theorists that people should have the freedom to do whatever they want with their own money as long as they are not harming others or diminishing their rights and opportunities. This view is exemplified in socalled "right to try" laws now passed in 22 states. These laws are justified by the claim that terminally ill patients should be free to try-and pay companies for access to-experimental drugs not approved by FDA in the hope of finding a cure. Their decision might generate benefits for themselves and harms no one else.

Such arguments might be extended to the research context as well. Requiring payment to participate in a research study that otherwise would not be conducted does not obviously hurt any other people, and those who do not wish to pay, or who lack the means, are free to decline. After all, no one has a right to unproven, experimental interventions. Thus, as long as people voluntarily consent to pay for the opportunity to participate in research, a parallel to right-to-try arguments based on personal freedom provides a strong rationale for allowing them to do so.

\section{ARGUMENTS AGAINST PAY TO PLAY}

There are several arguments against permitting payment for participation. First, pay-to-play research is less likely to be a collaborative partnership than a psychological exploitation of individuals desperate to do anything to save their own or a loved one's life (10). Although willingness to pay might indicate understanding and voluntariness by participants, it might also reveal unrealistic expectations and undue pressure. The chances for success of earlyphase experimental drugs are much smaller than either researchers or laypeople think. The vast majority of experimental agents, $\sim 90 \%$, that enter human trials even under current circumstances fail primarily for reasons of safety and efficacy (11). A payto-play model is likely to be used for earlystage trials, as in the precision-medicine test trial mentioned above-precisely the types of studies that are least likely to benefit individual participants. In contrast, if the research is promising or has significant supporting data, the clinical research is more likely to gain external funding from either public or private sources. The limited amount of data available for early-stage research trials also makes it difficult for potential participants to assess their chances of receiving personal benefits. Many people who would pay to enroll in such trials are unlikely to be familiar with the data that describe the potential benefits and are thus likely to overestimate the chances of a successful outcome (12).

More importantly, desperate patients are likely to feel pressured to pay for participation, leading to biased decisionmaking that raises questions about voluntariness. For example, parents feel tremendous pressure to raise funds-perhaps by taking out a substantial loan or exhausting their retirement savings - to fund the participation of their ill child in a research study for a therapy they believe might be promising. Just because people can payor raise - substantial sums does not mean they cannot be taken unfair advantage of, especially if their illness or that of a loved one compromises or biases their decisionmaking (12). Typically, in such circumstances, society protects individuals from potential abuse.

In addition, collaborative partnership in research means that both sides are working toward a common goal of collecting generalizable data that can be used to enhance health. But as was observed in bone marrow transplantation trials for breast cancer (see below) (13), it is likely that the paying participants will be less willing to accept randomization to a placebo or active control arms-as used in some phase 1 and 2 and most phase 3 clinical trials-and more likely to demand studies that benefit themselves. This is less a collaborative partnership than a mutually beneficial transaction-a business deal.

Calling pay to play charity mischaracterizes personal consumption of a good or service. Buying into a clinical trial ultimately constitutes the purchasing of a good or service that happens to contribute social value as a side effect. Rather than charity, it is more analogous to buying an electric car, a choice that is clearly personal consumption even if it has the positive externality of combating climate change. Pay-to-play research is also different from a patient 
who donates to a charity that supports research. Typically, a donor does not fund a specific research project or buy a spot in a study, and the intermediation of a foundation or organization insulates researchers from pressure to enroll specific individuals. More broadly, when contributing to charity, one typically does not expect any quid pro quo beyond acknowledgment or an expression of gratitude.

Paying for research participation might actually undermine social value and scientific validity by skewing research priorities or encouraging methodologically inferior research. Whatever its limitations, one of the critical functions of peer review is the comparative assessment of the worthiness and methodological rigor of alternative research projects. Peer reviewers can evaluate the potential social benefit of research and prioritize longer-term but more beneficial projects. Pay-to-play funding would prioritize research needs of the wealthy and their ailments. These priorities are unlikely to align with research that might be worthy but afflict individuals without the means to pay, such as interventions for lead poisoning, tuberculosis, or schistosomiasis. If successful, pay-to-play research could also skew researchers and research institutions to pursue lucrative studies that are not necessarily socially valuable. This might lead to a brain and facilities drain. Last, pay-to-play funding might enable studies that ask important questions but lack the methodological rigor to survive traditional peer review. At the extreme, pay-to-play arrangements might enable charlatans to pursue-and profit from-flawed trials that offer no, or even negative, social value (4-6).

Another argument against paying for participation is fair subject selection. Markets distribute goods and services according to one's ability to pay. However, the selection of research participants should be based on the goals of the research study, including maximizing internal validity and generalizability, and on the obligation to minimize risks (7). Just as risky research should not target vulnerable groups, promising research should not be reserved for the wealthy or privileged (7).

In a 1998 article, the New York Times reported on the first antiangiogenesis factor undergoing clinical trials (14) and described the biologic as a "cure" for cancer. The next day, cancer centers conducting the phase I trial were besieged by thousands of people wanting to enroll (15). Those centers did not select the well-connected and well-off or auction off the places on the study (15). A free society prohibits certain goods and services from being bought and sold or distributed on the basis of wealth. The ability to vote and grades on tests and papers in college courses should be based on rights or merit, not distributed to the highest bidder. Similarly, in the United States, a person cannot legally buy an organ for transplantation, purchase admission to the last bed in the intensive care unit, or buy a dose of a scarce vaccine in an influenza epidemic. Society is concerned about socioeconomic disparities in access to health care and health outcomes as well as in enrollment in research studies. Selection of participants for a research study by ability to pay violates fair subject selection.

In determining the risk-benefit ratio of a study, IRBs are supposed to consider psychological, social, economic, and physical risks. For instance, the disclosure of medical information might lead to loss of a job or the inability to acquire disability or life insurance, which are risks of research participation. In the context of pay-to-play arrangements, the IRB would have to determine whether the potential direct benefits and knowledge gains from the research justify the financial losses to participants that are associated with enrolling in the trial, as well as whether any risks could be justified if the study might not be able to recruit an adequate number of paying participants and therefore must be abandoned.

Pay-to-play arrangements also create challenges for the ethical implementation of a research study. Having a participant pay could lead to the bending of inclusion criteria, pressure on investigators not to remove participants from a study, and even inappropriate influences on decisions to terminate a study. For instance, it is not hard to imagine a pay-to-play participant pressuring a researcher to grant an exception to inclusion criteria and a researcher agreeing to do so because of the additional financial support. Similarly, patients with limited therapeutic options sometimes demand access to drugs even after studies have proven them to be ineffective. Finally, the paying participants might be reluctant to fully disclose symptoms and side effects. Having invested substantial sums, participants may not want to acknowledge problems that might result in their exclusion or removal from a study.
In the past, attempts to rapidly expand access to promising but still unproven experimental treatments undermined the conduct and completion of research studies because patients were unwilling to accept randomization that might lead to their not receiving experimental treatments. For instance, in the 1990s, patients demanded access to bone marrow transplantation for metastatic breast cancer. The treatment was unproven, but under pressure from patients, states passed laws to require coverage by insurers. This dramatically impeded trial enrollment because patients wanted to receive the transplant and did not want to risk receiving the control treatment as part of a trial. Ultimately, trials showed that bone marrow transplantation for breast cancer, with its high morbidity and mortality rates, was no better than typically used chemotherapy. The delay in completing the trial subjected many women to serious harm for no benefits (13).

The pay-to-play model has a high likelihood of undermining the research enterprise by (i) skewing the types of studies pursued as well as the amount of time researchers and facilities devote to particular projects; (ii) exploiting potential human subjects; and (iii) compromising the methodological rigor of clinical studies. Thus it is not accurate to claim that no one is harmed by people's exercise of their freedom. We are all harmed when the integrity of clinical research is compromised.

\section{PROHIBITING PAY TO PLAY}

Researchers are understandably frustrated with the diminishing support for clinical trials and the increasing competition for limited research resources. However, charging people to participate in research is likely to undermine the fundamental ethical bases of clinical research (7), especially the principles of social value, scientific validity, and fair subject selection. Furthermore, pay to play imposes unjustified financial harms on and raises the specter of exploitation of trial participants and their families. Researchers who offer the wealthy preferential access to places in research studies or who entice people to mortgage their homes so they can participate in clinical research take unfair advantage of people at a time when their judgment is potentially compromised.

This specter carries with it a strong ethical presumption against pay-to-play clinical research. Legislation or regulation to 
prohibit pay-to-play clinical studies is warranted to protect trial participants and the research enterprise.

\section{REFERENCES AND NOTES}

1. T. Lemmens, C. Elliott, Guinea pigs on the payroll: The ethics of paying research subjects. Account. Res. 7, 3-20 (1999).

2. N. Dickert, C. Grady, What's the price of a research subject? Approaches to payment for research participation. N. Engl. J. Med. 341, 198-203 (1999).

3. L. Stunkel, M. Benson, L. McLellan, N. Sinaii, G. Bedarida, E. Emanuel, C. Grady, Comprehension and informed consent: Assessing the effect of a short consent form. IRB 32 1-9 (2010). 6.

4. S. E. Lind, Fee-for-service research. N. Engl. J. Med. 314, 312-315 (1986).

5. H. Mclntosh, Providing experimental therapies as a commercial venture fails. J. Natl. Cancer Inst. 82, 84-87 (1990).
6. D. Sipp, Pay-to-participate funding schemes in human cell and tissue clinical studies. Regen. Med. 7 (suppl.), 105-111 (2012).

7. E. J. Emanuel, D. Wendler, C. Grady, What makes clinical research ethical? JAMA 283, 2701-2711 (2000).

8. U.S. Food and Drug Administration, Expanded access (compassionate use); available at www.fda.gov/NewsEvents/ PublicHealthFocus/ExpandedAccessCompassionateUse/ ucm20080392.htm.

9. C. E. Cryder, A. John London, K. G. Volpp, G. Loewenstein, Informative inducement: Study payment as a signal of risk. Soc. Sci. Med. 70, 455-464 (2010).

10. J. S. Hawkins, E. J. Emanuel, Clarifying confusions about coercion. Hastings Cent. Rep. 35, 16-19 (2005).

11. M. Hay, D. W. Thomas, J. L. Craighead, C. Economides, J. Rosenthal, Clinical development success rates for investigational drugs. Nat. Biotechnol. 32, 40-51 (2014).

12. J. Halpern, When concretized emotion-belief complexes derail decision-making capacity. Bioethics 26, 108-116 (2012).
13. R. A. Rettig, P. D. Jackson, C. M. Farquhar, W. M. Aubry, False hope: bone marrow transplantation for breast cancer. (Oxford University Press, New York, 2007).

14. G. Kolata, A cautious awe greets drugs that eradicate tumors in mice. New York Times 3 May 1998; available at www.nytimes.com/1998/05/03/us/hope-lab-specialreport-cautious-awe-greets-drugs-that-eradicatetumors-mice.html.

15. R. D. Pentz, A. L. Flamm, J. Sugarman, M. Z. Cohen, G. Daniel Ayers, R. S. Herbst, J. L. Abbruzzese, Study of the media's potential influence on prospective research participants' understanding of and motivations for participation in a high-profile phase I trial. J. Clin. Oncol. 20, 3785-3791 (2002).

10.1126/scitransImed.aac5204

Citation: E. J. Emanuel, S. Joffe, C. Grady, D. Wendler, G. Persad, Clinical research: Should patients pay to play? Sci. Transl. Med. 7, 298ps16 (2015). 